\title{
Case report of unexpected gastrointestinal involvement in type 1 Gaucher disease: comparison of eliglustat tartrate treatment and enzyme replacement therapy
}

Yoo-Mi Kim', Dong Hoon Shin ${ }^{2}$, Su Bum Park ${ }^{3}$, Chong Kun Cheon ${ }^{1,6^{*}}$ and Han-Wook Yoo ${ }^{4,5^{*}}$

\begin{abstract}
Background: Gastrointestinal involvement in Gaucher disease is very rare, and appears to be unresponsive to enzyme replacement therapy (ERT).

Case presentation: Here, we describe identical twin, splenectomized, non-neuronopathic Gaucher patients on long-term ERT for 9 years, who complained of epigastric discomfort due to Gaucher cell infiltration of the gastroduodenal mucosa. Rare compound heterozygous mutations (p.Arg48Trp and p.Arg257GIn) of the GBA gene were found in both. Improvement in the gastroduodenal infiltration and reduced chitotriosidase levels were observed in one who switched to eliglustat tartrate for 1 year, whereas the other one who maintained ERT showed no improvement of chitotriosidase level and persistent duodenal lesions.
\end{abstract}

Conclusion: This shows that eliglustat might be an effective treatment for Gaucher disease patients having lesions resistant to ERT.

Keywords: Gaucher disease, Duodenal involvement, Enzyme replacement therapy, Eliglustat tartrate

\section{Background}

Gaucher disease (GD) is an autosomal recessive lysosomal storage disorder resulting from a deleterious mutation in the GBA gene encoding $\beta$-glucosidase [1]. A deficiency in this enzyme leads to the accumulation of glycosphingolipids in the reticuloendothelial system (RES), resulting in anemia, thrombocytopenia, hepatosplenomegaly, skeletal deformation, and neurological impairment [2, 3]. Although enzyme replacement therapy (ERT) is an effective treatment for organomegaly, anemia, thrombocytopenia, and bone crisis, there are still unmet GD needs and co-morbidities despite ERT [4-6]. Moreover, unusual organ involvement, such as the lungs, mesenteric lymph nodes, or gastrointestinal (GI) tract, is difficult to treat with ERT. Herein, we

\footnotetext{
* Correspondence: chongkun@pusan.ac.kr; hwyoo@amc.seoul.kr ${ }^{1}$ Department of Pediatrics, College of Medicine, Pusan National University Children's Hospital, Yangsan, Korea

${ }^{4}$ Medical Genetics Center, Asan Medical Center, University of Ulsan College of Medicine, Seoul, Korea

Full list of author information is available at the end of the article
}

report unusual GI mucosal involvement in identical twin Korean siblings with non-neuronopathic GD during long-term ERT, and clinical improvement 1 year after the administration of eliglustat tartrate.

\section{Case report \\ Subject 1}

A 35-year-old man, the elder of identical twins, was diagnosed with GD at the age of 9 years old via a bone marrow biopsy, when he was brought to medical attention because of hepatomegaly and recurrent osteomyelitis. The patient underwent a splenectomy at the age of five because of progressive massive splenomegaly and thrombocytopenia. He began ERT treatment (imiglucerase, Cerezyme $^{\circ}$ ) at age 26, when this treatment became available. The patient received ERT at a dosage of 60 units $/ \mathrm{kg}$ every other week, and was referred to our hospital; however, he transiently received onehalf of a dose of ERT during the global enzyme shortage for 2 years. He did not show any neurological signs, 
including impaired initiation of saccades, horizontal gaze palsy, seizure, or cognitive decline, but his white blood cell glucocerebrosidase activity was $1.1 \mathrm{nmol} / \mathrm{h} / \mathrm{mg}$ (normal 10.3-41.8). He was subjected to direct sequencing of the $G B A$ gene, which showed the compound heterozygous mutations c.259C > T (p.R48W) and c.5118G > A (p.R257Q). The laboratory findings, including biomarkers, showed levels with the normal ranges: hemoglobin $15.5-16 \mathrm{mg} / \mathrm{dl}$ (normal 14-17), platelet count 190,000-200,000/ $\mu \mathrm{l}$ (normal 140,000-400,000), acid phosphatase 2.5-5.2 U/1 (normal 0-6.6), and angiotensin-converting enzyme (ACE) 47-58 U/l (normal 20-70). The chitotriosidase level was $958.6 \mathrm{nmol} / \mathrm{h} / \mathrm{ml}$ (normal 4-76) during his visit to our hospital. His previous result could not be obtained.

Although this patient had been on ERT for more than 9 years, the skeletal involvement progressed to avascular necrosis of the hip joint; however, he complained of epigastric discomfort and poor weight gain. Over the past 2 years, his body weight slowly decreased from $48 \mathrm{~kg}$ (body mass index [BMI], $18.7 \mathrm{~kg} / \mathrm{m}^{2}$ ) to $42 \mathrm{~kg}$ (BMI, $16.4 \mathrm{~kg} / \mathrm{m}^{2}$ ), and he was unable to consume pills or food easily because of epigastric discomfort. His pain was aggravated by spicy food. Despite the weight loss, his total protein level was 7.1-7.6 gm/mL (normal 6.6-8.3). An upper GI endoscopy for dyspepsia was performed by a local hospital 2 years previously, revealing mild gastritis. Due to the intractable epigastric discomfort, the upper GI endoscopy was followed up, and showed multiple nodular yellowish lesions on the duodenum (Fig. 1a). The pathological findings of the biopsy specimen revealed that the nodular lesions consisted of Gaucher cell infiltration, and stained positively with CD68 (Fig. 1i-l).

The immunoglobulin G (IgG) antibody against imiglucerase was negative, and we gradually increased the dose of imiglucerase from 60 units/kg to 100 units $/ \mathrm{kg}$ every other week. Despite the high dose of ERT for 6 months, a mild reduction in the chitotriosidase level (from 752.5 to $695.3 \mathrm{nmol} / \mathrm{h} / \mathrm{ml}$ ) was observed, but the upper GI endoscopy showed that the duodenal lesions remained unchanged (Fig. 1b). Additional colonoscopy and wholebody magnetic resonance imaging (MRI) did not show any new lesions, including mesenteric lymph node involvement. After CYP2D6 genotyping, which revealed an extensive metabolizer, was conducted, the ERT was switched to eliglustat tartrate (supported by Sanofi Genzyme through the named patient program) at $100 \mathrm{mg}$ (84 $\mathrm{mg}$ for eliglustat alone) two times daily. Every 6 months, an upper GI endoscopy and blood testing for biomarkers were conducted during substrate reduction therapy (Fig. 1c and d). After 1 year of eliglustat tartrate treatment, the upper GI endoscopy showed gross improvement in the duodenal lesions (Fig. 1d), a remarkable reduction in the chitotriosidase levels (from 717.5 to $257.5 \mathrm{nmol} / \mathrm{h} / \mathrm{ml}$ ), and an increased body weight (to $50 \mathrm{~kg}$, BMI $19.5 \mathrm{~kg} / \mathrm{m}^{2}$ ). No adverse events were observed from the eliglustat tartrate treatment.

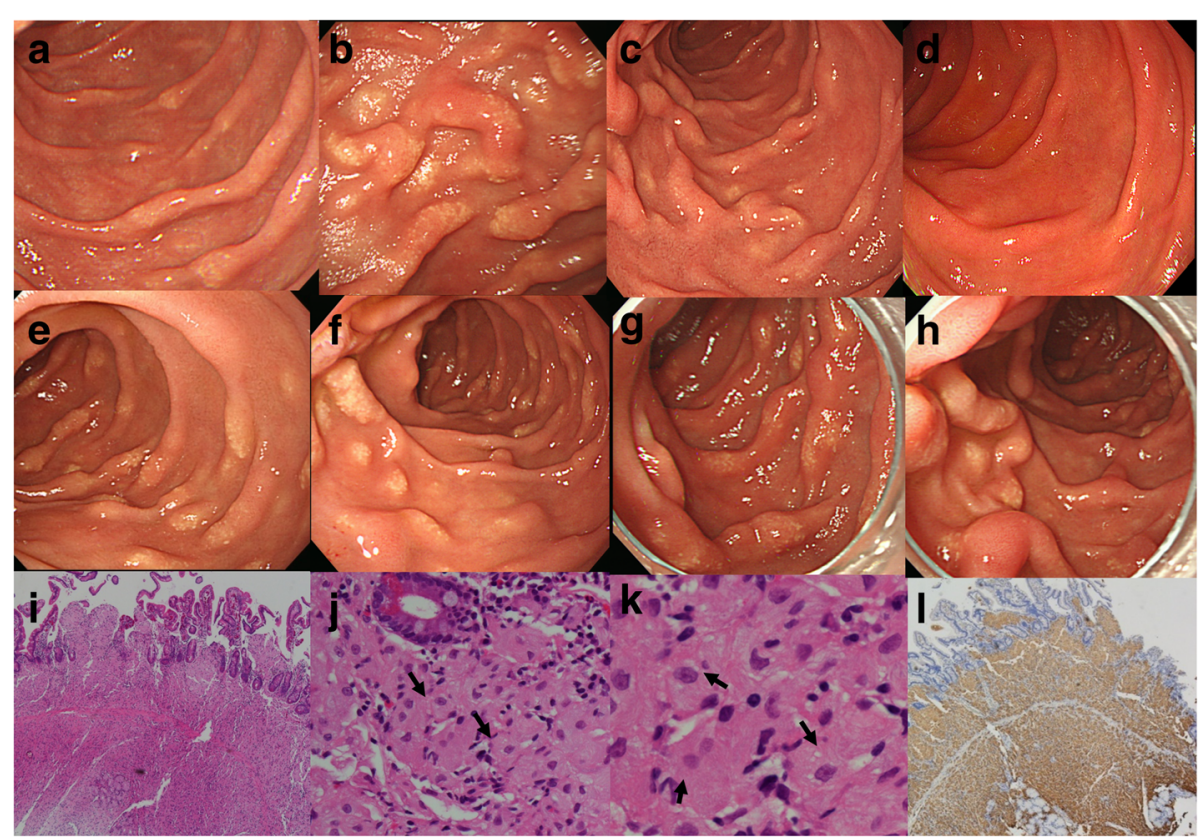

Fig. 1 Gross and pathological findings of the duodenal mucosa in Cases 1 and 2. Gaucher cell infiltration presenting with multiple yellowish nodular lesions in the upper gastrointestinal (Gl) endoscopy at baseline (a), persistent lesions 6 months after a high dose of enzyme (b), slightly improving multiple nodular lesions at 6 months (c), and grossly improving at 12 months (d) after eliglustat tartrate administration in Case 1. Persistent multiple nodular lesions in Case 2 at baseline $(\mathbf{e}, \mathbf{f})$, and 12 months $(\mathbf{g}, \mathbf{h})$ after ERT. Gaucher cell infiltration in the duodenal mucosa at baseline $(H \& E, \times 40, \times 200, \times 400)$ $(\mathbf{i}, \mathbf{j}, \mathbf{k})$. Gaucher cells are strongly positivity for CD68, which is a special stain for macrophages and Gaucher cells $(C D 68, \times 40)(\mathbf{I})$ 


\section{Subject 2}

A 35-year-old man, the younger of identical twins, was diagnosed with GD at the age of 9 years old via a bone marrow biopsy, when he presented with hepatomegaly and recurrent osteomyelitis. At the age of 5 years old, he underwent a splenectomy for massive splenomegaly. This patient had been receiving ERT with 60 units $/ \mathrm{kg}$ of imiglucerase every 2 weeks since he was 26 years old, and showed no neurological symptoms. He also experienced a dose reduction of ERT during the shortage period. The leukocyte glucocerebrosidase activity in this patient was $1.9 \mathrm{nmol} / \mathrm{h} / \mathrm{mg}$ (normal 10.3-41.8). He lost $6 \mathrm{~kg}$ in the past 2 years (body weight: $44 \mathrm{~kg}$ ), and his BMI decreased to $17.6 \mathrm{~kg} / \mathrm{m}^{2}$, although he did not complain of severe dyspepsia like his older brother did. His total protein was 7.0-7.5 gm/dl (normal 6.6-8.3). The chitotriosidase level during his visit to our hospital was $1335.7 \mathrm{nmol} / \mathrm{h} / \mathrm{ml}$. Other biomarkers, including ACE and acid phosphatase, were in normal.

An upper GI endoscopy was performed, and nodular yellowish lesions on the duodenal mucosa indicated Gaucher cell infiltration. The IgG antibody against imiglucerase was also negative in this patient. As subject 2 was concerned about adverse events and the effectiveness of a high dose of ERT or eliglustat, he did not want to increase the dosage of ERT or switch to eliglustat tartrate as his older brother had. Thus, the 60 units $/ \mathrm{kg}$ dose of imiglucerase every 2 weeks was maintained. This subject's chitotriosidase level decreased from 1038.3 to $950.4 \mathrm{nmol} / \mathrm{h} / \mathrm{ml}$ during same first 6 months of ERT, which was higher in the older brother, but the latest chitotriosidase level was still high $(815.1 \mathrm{nmol} / \mathrm{h} / \mathrm{ml})$ when compared to the chitotriosidase level of the older brother treated for 1 year with eliglustat tartrate. Although his weight increased to $47 \mathrm{~kg}$ over 1 year, the recent upper GI endoscopy demonstrated persistent duodenal lesions in spite of the regular ERT (Fig. 1e-g). The colonoscopy and whole-body MRI did not indicate any additional lesions.

\section{Discussion}

ERT has been proven safe and effective for visceromegaly, anemia, thrombocytopenia, and skeletal symptoms related to GD [1, 3-6], and it reduces the blood levels of the acid phosphatase, ACE, and chitotriosidase biomarkers [7]. However, several factors may have caused the unusual manifestations seen in these twin brothers, despite longterm ERT. First, the splenectomies might have aggravated the bone lesions and unusual organ involvement. In the present cases, the splenectomy was performed at 5 years old, and recurrent osteomyelitis was observed throughout childhood. Since the inception of ERT, a splenectomy has been contraindicated in cases of GD [1, 3, 4], because it increases the risk for co-morbidities via systemic infection, malignancy, cholelithiasis, pulmonary hypertension, or hepatopulmonary syndrome [2, 5-8]. In addition, it can accelerate neurological debilitation and aggravate bone disease, such as avascular necrosis of the femur neck $[6,8]$. As the spleen may be a main reservoir for Gaucher cells in patients with GD, a splenectomy may aggravate the Gaucher cells to move to other organs, such as the lungs, lymphoid system, liver, GI tract, or bone marrow.

Second, the remarkable delay between the diagnosis and initiation of ERT was a critical factor, causing the constellation of severe clinical features. The third factor was that our twin brothers had unique mutations in the GBA gene, p.R48W and p.R257Q, which are rare. Although regarded as a mild mutation, p.R48W has been reported in non-neuronopathic GD manifesting bone disease, whereas p.R257Q has previously been reported in both acute neuronopathic and non-neuronopathic GD. Interestingly, p.R257Q was reported in a Type 2 Gaucher patient, and manifested with the infiltration of Gaucher cells throughout the body, including the brain, liver, lung, and GI tract [9]. Fourth, it seems that long-term ERT modifies the natural history of GD. For example, ERT-resistant mesenteric lymphadenopathies serve as sanctuary sites against ERT [10]. The mucosa of the GI tract may be resistant to ERT because of the relative scarcity of the mannose receptor [11]. Since the antibodies against imiglucerase were negative in our cases, the neutralizing antibody did not hamper clinical efficacy.

Since there are few reports on GI tract infiltration in GD (Table 1) [9, 12-15], no consensus guidelines on the treatment of these unusual cases have been suggested, and there are limitations for alternative treatments. We first tried to increase the dose from 60 units $/ \mathrm{kg}$ to 100 units $/ \mathrm{kg}$ in Case 1; however, this appeared to have little effect on reducing the Gaucher cell burden of the GI mucosa. Considering the fact that oral medication might reach and penetrate the GI mucosa better than imiglucerase, substrate reduction therapy (SRT) could have been an alternative treatment in the present cases. Miglustat was first introduced as an SRT, and showed an effectiveness similar to that of imiglucerase [16]. However, it had an adverse effect on the GI tract, including diarrhea, nausea, and vomiting, and limited indications for Gaucher disease when a patient was unable to use ERT. Eliglustat tartrate (Cerdelga ${ }^{\oplus}$ ) was approved by the US Food and Drug Administration in 2014. It is an active specific inhibitor of glucosylceramide synthase with limited toxicity, a good outcome, and stability in non-neuronopathic GD, even in patients switching from ERT [17-19]. We found that switching to eliglustat tartrate to reduce the mucosal involvement of the Gaucher cells was effective, and no adverse events were observed. 


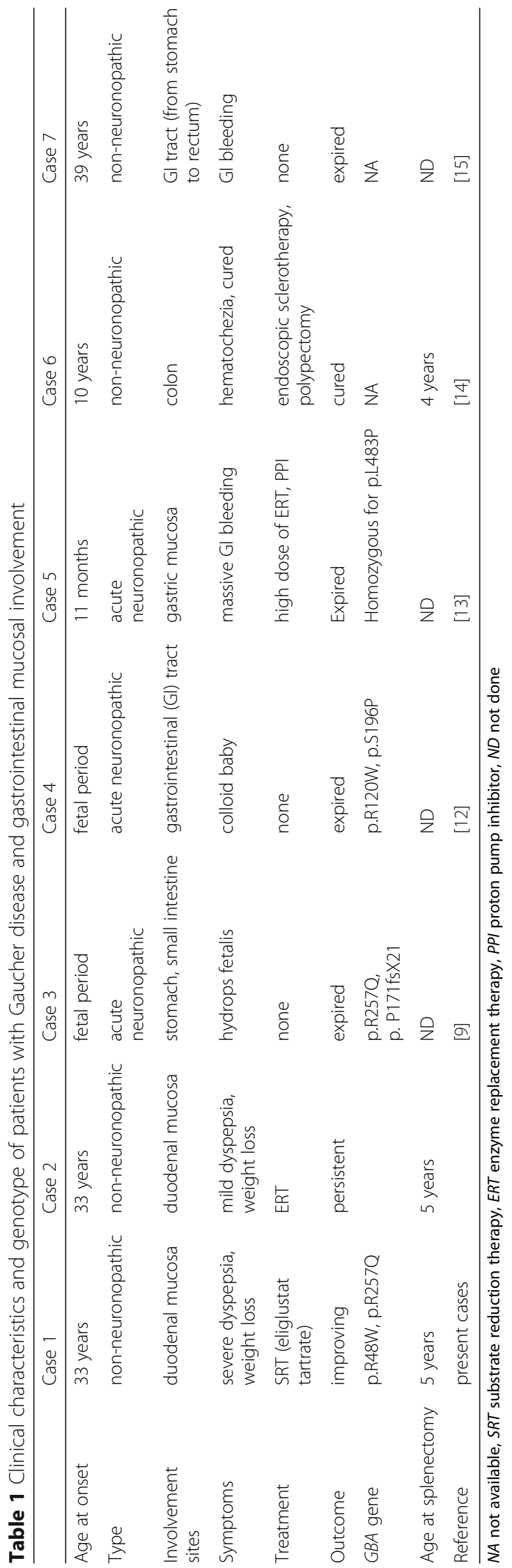


In summary, our report has clearly described the efficacy of oral SRT in one identical twin with GD. Both of these twins showed unusually persistent GI mucosal Gaucher cell infiltration, despite long-term ERT. Eliglustat tartrate may not only be a new alternative treatment for ERT, but also an effective therapy for patients especially resistant to ERT.

\section{Abbreviations}

ACE: Angiotensin-converting enzyme; BMI: Body mass index; ERT: Enzyme replacement therapy; GBA: $\beta$-glucosidase; GD: Gaucher disease; SRT: Substrate reduction therapy

\section{Acknowledgements}

The authors would like to thank the patients for participating in this study, which was supported by a research grant from Pusan National University Yangsan Hospital. We thank Sanofi-Genzyme for providing their patient named program.

\section{Funding}

No funding to declare.

\section{Availability of data and materials}

The datasets used and/or analysed during the current study available from the corresponding author on reasonable request.

\section{Authors' contributions}

Y-MK contributed to the management of patient, performed the data collection, the review of the literature and drafted the manuscript. DHS carried out the review of pathological studies and revised the manuscript about histologic finding. SBP performed the endoscopic procedure and supervised the manuscript about pathology. CKC and HWY both supervised the study and contributed equally as corresponding authors. All of the authors read and approved the final manuscript.

\section{Competing interests}

The authors declare that they have no competing interests.

\section{Consent for publication}

Written informed consent was obtained from the patient for publication of this case report and any accompanying images.

\section{Ethics approval and consent to participate}

The institutional review boards of Pusan National University Yangsan Hospital approved mutation analysis and clinical review of the patient (IRB No. 052015-068). A written informed consent was obtained from the patient to the participation in this study.

\section{Publisher's Note}

Springer Nature remains neutral with regard to jurisdictional claims in published maps and institutional affiliations.

\footnotetext{
Author details

${ }^{1}$ Department of Pediatrics, College of Medicine, Pusan National University Children's Hospital, Yangsan, Korea. ${ }^{2}$ Department of Pathology, College of Medicine, Pusan National University Yangsan Hospital, Yangsan, Korea. ${ }^{3}$ Department of Internal Medicine, College of Medicine, Pusan National University Yangsan Hospital, Yangsan, Korea. ${ }^{4}$ Medical Genetics Center, Asan Medical Center, University of Ulsan College of Medicine, Seoul, Korea. ${ }^{5}$ Department of Pediatrics, Asan Medical Center Children's Hospital, University of Ulsan College of Medicine, 88, Olympic-ro 43-gil, Songpa-gu, Seoul 138-736, Korea. ${ }^{6}$ Department of Pediatrics, Pusan National University Children's Hospital, Pusan National University School of Medicine, Geumo-ro, Yangsan-si, Gyeongnam 602-739, Korea.
}

Received: 20 December 2016 Accepted: 7 April 2017

Published online: 15 May 2017

\section{References}

1. Cox TM. Gaucher disease: clinical profile and therapeutic developments. Biologics. 2010;4:299-313.

2. Thomas AS, Mehta A, Hughes DA. Gaucher disease: haematological presentations and complications. Br J Haematol. 2014;165:427-40.

3. Nagral A. Gaucher disease. J Clin Exp Hepatol. 2014;4:37-50.

4. Charrow J. Enzyme replacement therapy for Gaucher disease. Expert Opin Biol Ther. 2009;:121-31

5. Anderson L, Henley W, Wyatt KM, Nikolaou V, Hughes DA, Waldek S, et al. Long-term effectiveness of enzyme replacement therapy in adults with Gaucher disease: results from the NCS-LSD cohort study. J Inherit Metab Dis. 2014:37:953-60.

6. Charrow J, Scott CR. Long-term treatment outcomes in Gaucher disease. Am J Hematol. 2015;90:S19-24.

7. Elstein D, Zimran A. Review of the safety and efficacy of imiglucerase treatment of Gaucher disease. Biologics. 2009;3:407-17.

8. Ortolano S, Viéitez I, Navarro C, Spuch C. Treatment of lysosomal storage diseases: recent patents and future strategies. Recent Pat Endocr Metab Immune Drug Discov. 2014:8:9-25.

9. Park HW, Lee Y, Kim GH, Lee BS, Kim KS, Yoo HW, et al. Novel frameshift mutation (Pro171fsX21) in neonatal type 2 Gaucher's disease. Gene. 2012;507:170-3.

10. Lee BH, Kim DY, Kim GH, Cho KJ, Yoon HK, Yoo HW. Progressive mesenteric lymphadenopathy with protein-losing enteropathy; a devastating complication in Gaucher disease. Mol Genet Metab. 2012;105:522-4.

11. Nissley P, Kiess W, Sklar M. Developmental expression of the IGF-II/mannose 6-phosphate receptor. Mol Reprod Dev. 1993;35:408-13.

12. Stone DL, Carey WF, Christodoulou J, Sillence D, Nelson P, Callahan M, et al. Type 2 Gaucher disease: the collodion baby phenotype revisited. Arch Dis Child Fetal Neonatal Ed. 2000;82:F163-6.

13. Hoffmann B, Schwahn B, Knobbe CB, Vogel M, Blohm M, Mayatepek E, et al. Acute neuronopathic Gaucher disease complicated by fatal gastrointestinal bleeding. Neuropediatrics. 2006;37:163-5.

14. Henderson JM, Gilinsky NH, Lee EY, Greenwood MF. Gaucher's disease complicated by bleeding esophageal varices and colonic infiltration by Gaucher cells. Am J Hematol. 1991;86:346-8.

15. Yamadori I, Morikawa T, Kobayashi S, Ohmori M. Gaucher's disease type I. Report of a case with prominent deposition of ceroid in splenic endothelial cells and intestinal smooth muscle fibers. Acta Pathol Jpn. 1990;40:425-30.

16. Weinreb NJ, Barranger JA, Charrow J, Grabowski GA, Mankin HJ, Mistry P. Guidance on the use of miglustat for treating patients with type 1 Gaucher disease. Am J Hematol. 2005;80:223-9.

17. Shayman JA. Eliglustat tartrate: glucosylceramide synthase inhibitor treatment of type 1 Gaucher disease. Drugs Future. 2010;35:613-20.

18. Mistry PK, Lukina E, Ben Turkia H, Amato D, Baris H, Dasouki M, et al. Effect of oral eliglustat on splenomegaly in patients with Gaucher disease type 1: the ENGAGE randomized clinical trial. JAMA. 2015:313:695-706.

19. Cox TM, Drelichman G, Cravo R, Balwani M, Burrow TA, Martins AM, et al. Eliglustat maintains long-term clinical stability in patients with Gaucher disease type 1 stabilized on enzyme therapy. Blood. 2016. do:10.1182/ blood-2016-12-758409.

Submit your next manuscript to BioMed Central and we will help you at every step:

- We accept pre-submission inquiries

- Our selector tool helps you to find the most relevant journal

- We provide round the clock customer support

- Convenient online submission

- Thorough peer review

- Inclusion in PubMed and all major indexing services

- Maximum visibility for your research

Submit your manuscript at www.biomedcentral.com/submit
) Biomed Central 